\title{
Congenital Erythropoietic Porphyria: A Rare Case of Photosensitivity with Hemolytic Anaemia and Mental Retardation
}

\author{
Nadia Shirazi1, Payal Chauhan², Rashmi Jindal2 and Sohaib Ahmad³
}

\begin{abstract}
Congenital erythropoietic porphyria, also called Günther's disease, is a very rare genetic autosomal recessive disease affecting less than 1 per 1,000,000 children. Pathogenesis involves genetic mutation encoding uroporphyrinogen-III cosynthase which leads to accumulation of porphyrin in many tissues, leading to extreme skin photosensitivity, red cell lysis, splenomegaly and reduced life expectancy. Herein, we report a 12-year mentally challenged girl with multiple blisters and scars on sun exposed sites since birth. She had hepatomegaly, erythrodontia, severe anaemia with haemolytic blood picture and mildly elevated liver enzymes. Skin biopsy showed deposition of amorphous eosinophilic porphyrins in the dermis, thus confirming a diagnosis of congenital erythropoietic porphyria.
\end{abstract}

Key Words: Günther's disease, Erythrodontia, Skin biopsy, Wood's lamp.

\section{INTRODUCTION}

The word "porphyria" is derived from the Greek word "porphura", which means "purple pigment". Congenital Erythropoietic porphyria (CEP), first described by Günther in 1911, is a rare inborn error of haem synthesis inherited as autosomal recessive disorder. ${ }^{1}$ It is characterised by deficiency of uroporphyrinogen-III cosynthase (UROS-III) enzyme, which is the fourth enzyme in the heme biosynthesis pathway. This is responsible for isomerisation of hydroxymethyl bilane I and accumulation of biologically inert type I porphyrins, particularly coproporphyrin I and uroporphyrin I, mainly in skin, red blood cells, bones and teeth. These porphyrins induce oxygen dependent/phototoxic damage characterised by subepidermal skin blistering with moderate to intense inflammation, ulceration and development of deforming scars on all sun exposed areas like face, neck, scalp, arms and feet. ${ }^{2}$

There are less than 200 cases of CEP reported worldwide and less so from the Indian subcontinent. We report herein a 12-year girl with multiple blisters, reddish-brown discolouration of teeth and nails, mental retardation with severe haemolytic anaemia and also briefly review the relevant literature.

\section{CASE REPORT}

A 12-year female child, born out of non-consanguinous marriage, presented with multiple atrophic scars and

Department of Pathologyl / Dermatology / General Medicine ${ }^{3}$, Himalayan Institute of Medical Sciences, Swami Rama Himalayan University, Jolly Grant, Dehradun, Uttarakhand, India

Correspondence: Dr. Nadia Shirazi, Department of Pathology, Himalayan Institute of Medical Sciences, Swami Rama

Himalayan University, Jolly Grant, Dehradun, Uttarakhand, 248140-India

E-mail: shirazinadia@gmail.com

Received: October 10, 2018; Accepted: November 20, 2018 blisters on face, scalp, hands and feet (sun exposed sites) since infancy (Figure 1). Parents also noticed reddish discoloration of urine since 10 days of age.

On examination, reddish brown teeth and few distorted finger and toe nails were seen. Her physical and mental development was subnormal for age. Corneal or conjunctival scarring was not present. Other family members and two siblings of the child were unaffected. Her spleen was enlarged $2 \mathrm{~cm}$ below the costal margin. No other systemic abnormality was detected. On Woods lamp examination of teeth, there was erythrodontia with a bright red fluorescence (Figure 2). Ultrasound revealed hepatosplenomegaly. Hemoglobin was $4.2 \mathrm{~g} / \mathrm{dL}$, total leukocyte count (TLC) $9800 / \mathrm{mm}^{3}$, differential white cell count (DLC), neutrophils $64 \%$, lymphocytes $32 \%$, eosinophils $2 \%$ and monocytes $2 \%$. Platelets were $80,000 / \mathrm{mm}^{3}$. Peripheral smear showed red cell mass reduction, moderate anisopoikilocytosis, polychromasia, target cells and schistocytes along with few nucleated red blood cells (RBCs). Liver function tests were mildly deranged and showed an elevated serum bilirubin, Aspartate transaminase (AST) and raised alkaline phosphatase. Urinary porphobilinogen, tested by the method of Schwartz et al. was negative. ${ }^{3}$ Her parents' urine and blood samples were screened; however, there was no evidence of porphyria in them. Skin biopsy from blisters showed atrophic epidermis and deposition of abundant eosinophilic acellular, Peridic acid schiff (PAS) positive substance in the dermis and around vessel walls (Figure $3 a$ and $3 b$ ), confirming a diagnosis of CEP.

The patient was discharged after 4 units blood transfusion to achieve adequate hemoglobin level. She was also advised to avoid sun exposure as much as possible, use topical sunscreens liberally and take oral $\beta$-carotene. The attendants refused bone marrow transplant because of financial constraints. Patient has been asked to come for regular follow-ups for symptomatic therapy. 


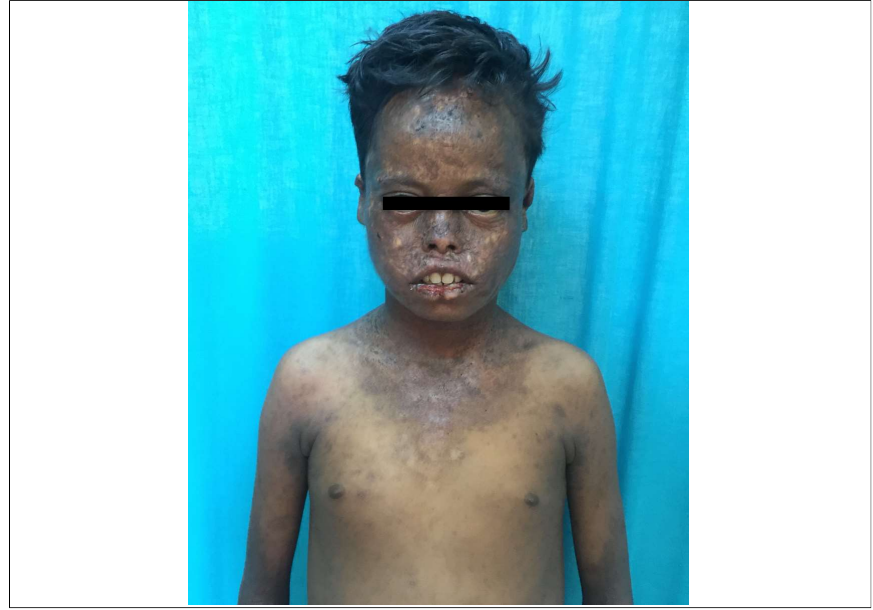

Figure 1: Multiple mutiliating scars and blisters on face, scalp, neck and arms.

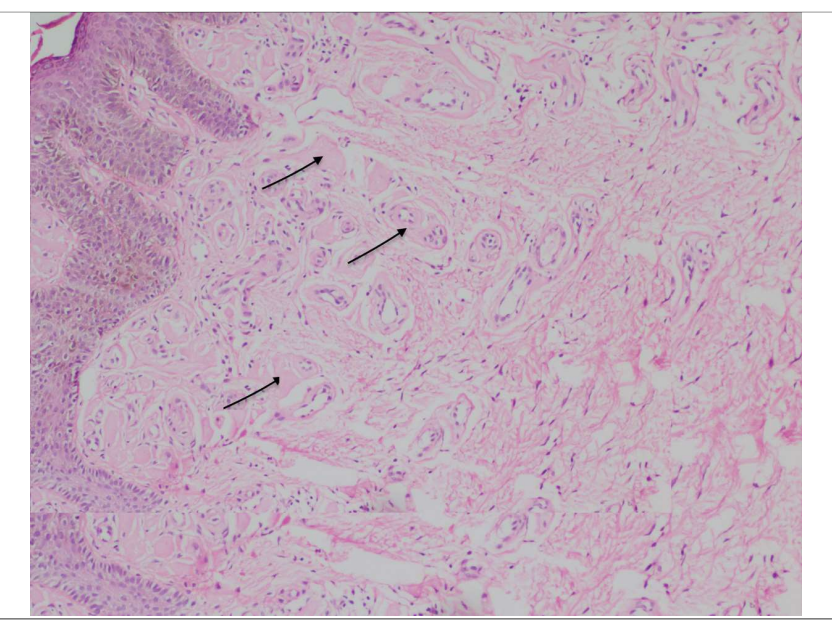

Figure 3a: Skin biopsy showing deposition of amorphous substance in dermis and around blood vessels (Hematoxylin \& Eosin: x200).

\section{DISCUSSION}

CEP usually begins in the neonatal period. Light in the Soret region band $(400-410 \mathrm{~nm})$ activates the biologically inert isomers of URO-I and COPRO-I enzymes, resulting in phototoxic, oxygen dependent damage causing skin fragility, blisters, milia, and mutilating scars. ${ }^{4}$ These patients are transfusion-dependent and show features of hypersplenism. In contrast, late onset cases have milder cutaneous symptoms, are not transfusion-dependent and may develop thrombocytopenia and myelodysplasia. ${ }^{5}$

Traditionally, the diagnosis was mostly based on classic clinical features or demonstration of various porphyrins on urine high performance liquid chromatography (HPLC) examination. This patient had severe hemolytic anaemia. However, De et al. reported a case of CEP without haemolysis. ${ }^{6}$ Mutation studies from India are less frequently described in published literature. However, a study from Vietnam revealed a V3F mutation (which decreases stability of the enzyme and results in $<1 \%$ of its activity), which has been described in Japanese but less commonly in Caucasians. ${ }^{7}$

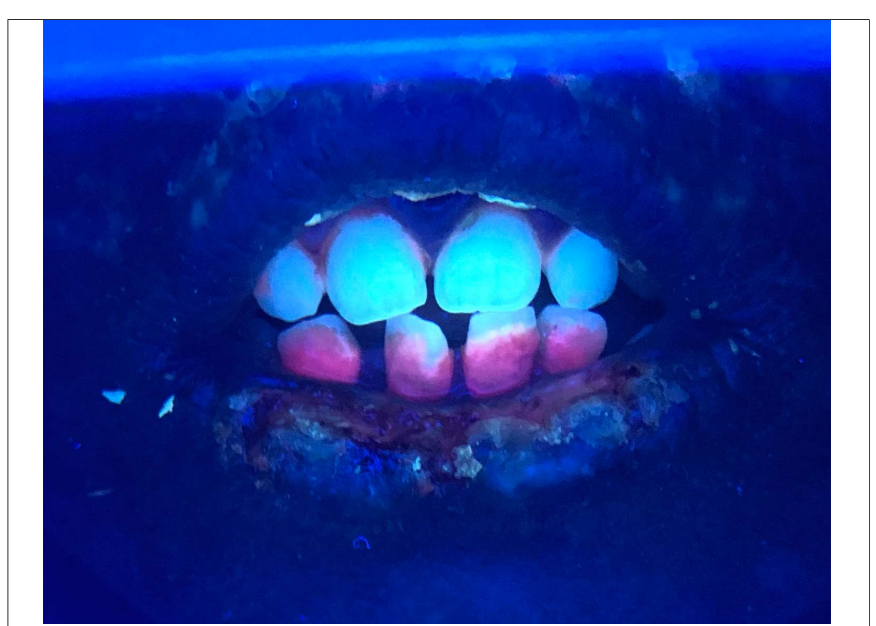

Figure 2: Woods lamp examination showing reddish brown discolouration of teeth.

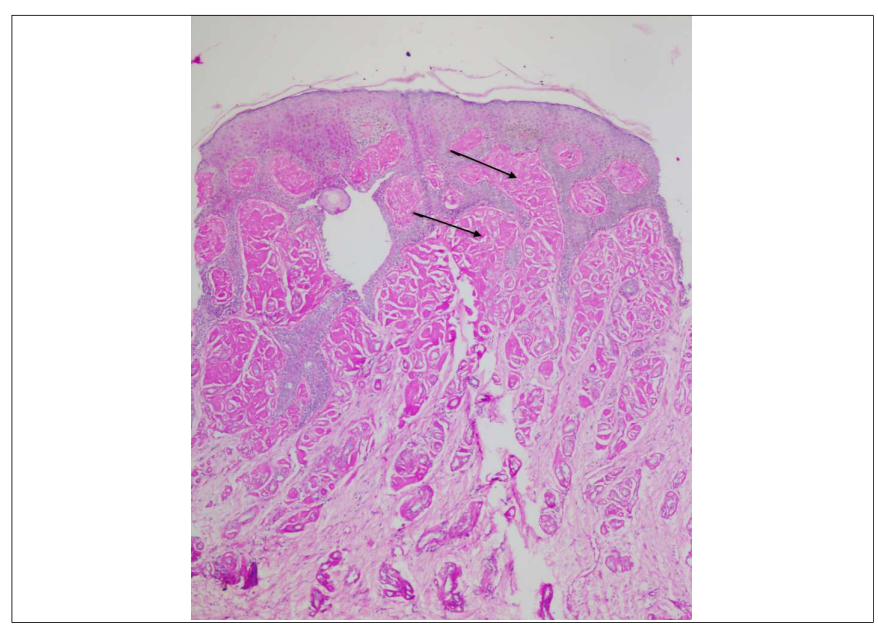

Figure 3b: Skin biopsy showing deposition of porphyrins (Periodic Acid Schiff: $\times 100)$.

Differential diagnosis includes epidermolysis bullosa (porphyrin levels are not raised), pseudoporphyria (drug induced but porphyrins are normal), porphyria cutanea tarda (which usually presents in adulthood with skin blistering but without erythrodontia) and hereditary coproporphyria (which is usually latent before puberty). ${ }^{8}$

Management involves strict sun avoidance with symptomatic therapy. Repeated blood transfusions for elevation of haemoglobin and splenectomy to counter hypersplenism have been tried, particularly in milder phenotypes. Bone marrow transplant is currently considered the best treatment option available. The new bone marrow cells, having the normal copy of UROS gene, will overtake the defective population of red cells and start producing normal erythroid precursors. ${ }^{9}$ Other treatment modalities without established efficacy include oral beta carotene, intravenous hematin, hydroxychloroquine, plasmapheresis, oral charcoal, other porphyrin binders and splenectomy. Studies focusing on isolation and characterisation of the UROS enzyme and gene are also underway. 10 Antenatal diagnosis can be made by measuring the uroporphyrin I concentration in the 
amniotic fluid, which is increased as early as 16 weeks in utero. Genetic counselling is important for the parents of an affected offspring. 10

In conclusion, blistering photosensitivity reactions in association with mental retardation are rarely reported. A high index of suspicion for the diagnosis of CEP is warranted in such cases.

\section{REFERENCES}

1. Günther H. Die Hamatoporphyrie. Deutsch Arch Klin Med 1911; 105:89-146.

2. Sarkany RP. The cutaneous porphyrias. In: Burns T, Breathnach S, Cox N, Griffiths C, Eds. Rook's textbook of dermatology. $8^{\text {th }}$ ed. West Sussex: Wiley-Blackwell publishers; 2010. p. 59.1-21.

3. Schwartz S, Berg M, Bossenmaier I, Dinsmore H. Determination of porphyrins in biological materials. In: Click D, Ed. Methods of biochemical analysis. New York: interscience publishers, Inc. 1960. p. 246.
4. Balwani M, Desnick RJ. The porphyrias: Advances in diagnosis and treatment. Blood 2012; 120:4496-504.

5. Kontos AP, Ozog D, Bichakjian C, Lim HW. Congenital erythropoietic porphyria associated with myelodysplasia presenting in a 72-year-old man: Report of a case and review of the literature. Br J Dermatol 2003; 148:160-4.

6. De AK, Das K, Sil A, Joardar S. A case of congenital erythropoietic porphyria without hemolysis. Indian J Dermatol 2013; 58:407.

7. Thien Kim DH, Kawazoe A, Bang PD, Thanh NT, Taketani S. Congenital erythropoietic porphyria: Mutation of the uroporphyrinogen III cosynthase gene in a Vietnamese patient. Case Rep Dermatol 2013; 5:105-10.

8. Bari AU. Congenital erythropoietic porphyria in three siblings. Indian J Dermatol Venereol Leprol 2007; 73:340-2.

9. Koley S, Saoji V. Congenital erythropoietic porphyria: Two case reports. Indian J Dermatol 2011; 56:94-7.

10. Dsnick RJ, Astrin HK. Congenital erythropoietic porphyria: advances in pathogenesis and treatment. British $\mathrm{J}$ Haematol 2002; 117:779-95. 